\title{
Prognostic value of human telomerase reverse transcriptase gene expression in oral carcinogenesis
}

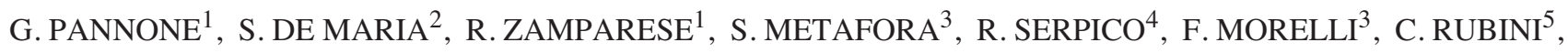 \\ E. FARINA ${ }^{4}$, M.CARTENI ${ }^{2}$, S. STAIBANO ${ }^{6}$, G. DE ROSA ${ }^{6}$, L. LO MUZIO ${ }^{1}$ and P. BUFO ${ }^{1}$ \\ ${ }^{1}$ Department of Surgical Sciences, University of Foggia, Foggia; ${ }^{2}$ Department of Biochemistry, Second University of Naples, \\ Naples; ${ }^{3}$ Institute of Genetics and Biophysics 'A. Buzzati Traverso', CNR Naples, Naples; ${ }^{4}$ Department of Oral Pathology, \\ Second University of Naples, Naples; ${ }^{5}$ Institute of Pathology, University of Ancona, Ancona; ${ }^{6}$ Department of \\ Biomorphological and Functional Sciences, Section of Surgical Pathology, University of Naples Federico II, Naples, Italy
}

Received December 5, 2006; Accepted January 30, 2007

\begin{abstract}
Human telomerase reverse transcriptase (hTERT) gene expression in resected specimens of oral squamous cell carcinoma (OSCC) and their surrounding tissue, either apparently normal or clearly histologically dysplastic, was evaluated by both real-time RT-PCR and immunohistochemical protein analyses. The expression level of hTERT in oral dysplasia and in OSCC was markedly higher than in normal tissues. The correlation between hTERT expression in OSCC and clinico-pathological parameters or survival of OSCC patients was statistically analyzed. Our study demonstrates that there is no significant relationship between hTERT expression and classical clinico-pathological parameters. Interestingly, survival analysis showed both overexpressing cases and lower survival rate in the early stage of OSCC ( $\mathrm{p}=0.03$ for immunohistochemistry; $\mathrm{p}=0.04$ for RT real-time PCR). The histological location of hTERT in these tumors has been discussed in the context of the cancer stem cell theory.
\end{abstract}

\section{Introduction}

The human telomerase is a complex RNA-protein heterotrimeric enzyme (hTR: human telomerase RNA, that acts as template in the process of repeat addition; TP1: telomeraseassociated protein 1 of unknown function; hTERT: human telomerase reverse transcriptase, the catalytic subunit of the complex), possessing an RNA-dependent DNA polymerase activity that is specialized in the synthesis and maintenance of the telomeric ends of linear chromosomes, protecting them from degradation and end-to-end fusion. hTERT expression

Correspondence to: Professor Lorenzo Lo Muzio, University of Foggia, Via Carelli 28, 71100 Foggia, Italy

E-mail:1lomuzio@tin.it

Key words: human telomerase reverse transcriptase, oral squamous cell carcinoma, tumor prognostic markers correlates well with telomerase activity. Diverse experimental models from yeast to human have proven that telomeres play a critical role in the maintenance of chromosomal integrity. Most human somatic cells do not express telomerase (1-3) even though they lose telomeric DNA with each cell division ultimately experiencing chromosomal instability, replicative senescence, and cell death (4,5). A weak hTERT expression, however, has been demonstrated to occur in highly proliferating tissues such as intestinal, endometrial, bronchial, and epidermal epithelia, activated $\mathrm{B}$ and $\mathrm{T}$ lymphocytes, regenerating liver, and germ cells $(1,6-10)$. In contrast, the great majority $(85 \%)$ of human tumors shows strong telomerase activity (1), expresses the gene encoding hTERT $(2,3,11)$, and maintains the length of their telomeres (12-14). Hahn et al have demonstrated that the ectopic expression of hTERT and two oncogenes (the simian virus 40 large-T oncoprotein and an oncogenic allele of H-ras) results in the direct tumorigenic conversion of normal human epithelial and fibroblast cells (14). The authors suggested also that the wide expression of hTERT in human tumors makes this protein a possible molecular target of anticancer treatment (15).

There is an overall agreement on the critical role played by telomerase in the mechanism of cell immortalization during the process of oral carcinogenesis both in vitro and in vivo (16). In particular, in a variety of oral dysplasias a marked hTERT ectopic expression has been detected as associated with other molecular changes, such as loss of INK4A and/or retinoic acid receptor- $\beta$, even in the absence of p53 mutations (16).

Goessel et al have recently created in vitro a human cellular model of oral-esophageal carcinogenesis using the genetic alterations frequently observed in the corresponding human cancer (17). In this interesting model a critical role in the process of malignant transformation of oral keratinocytes, transfected with recombinant retroviral DNA coding for cyclin D1, dnp53, c-myc and EGFR, is played by p53 inactivation and EGFR-induced activation of telomerase and P13K/AKT pathway (17). In addition, the recent increase in understanding the structure and function of telomeres and telomerase has led to the possible use of them as diagnostic and prognostic markers in several types of neoplasms including oral cancer 
Table I. Patient characteristics.

\begin{tabular}{|c|c|c|c|c|}
\hline \multicolumn{5}{|c|}{ Age (years) } \\
\hline \multicolumn{2}{|c|}{ Range } & \multicolumn{3}{|c|}{$42-81$} \\
\hline \multicolumn{2}{|c|}{ Mean } & \multicolumn{3}{|c|}{65} \\
\hline \multicolumn{5}{|c|}{ Gender } \\
\hline \multicolumn{2}{|c|}{ Male } & \multicolumn{3}{|c|}{25} \\
\hline \multicolumn{2}{|c|}{ Female } & \multicolumn{3}{|c|}{17} \\
\hline \multicolumn{5}{|c|}{ Size (cm) } \\
\hline \multicolumn{2}{|c|}{$\leq 1.5$} & \multicolumn{3}{|c|}{25} \\
\hline \multicolumn{2}{|c|}{$>1.5$} & \multicolumn{3}{|c|}{17} \\
\hline \multicolumn{5}{|c|}{ Recurrence } \\
\hline \multicolumn{2}{|l|}{ No } & \multicolumn{3}{|c|}{22} \\
\hline \multicolumn{2}{|c|}{ Yes } & \multicolumn{3}{|c|}{20} \\
\hline \multicolumn{5}{|l|}{ Site } \\
\hline \multicolumn{2}{|c|}{ Cheek } & \multicolumn{3}{|c|}{5} \\
\hline \multicolumn{2}{|c|}{ Mouth floor } & \multicolumn{3}{|c|}{6} \\
\hline \multicolumn{2}{|c|}{ Tongue } & \multicolumn{3}{|c|}{15} \\
\hline \multicolumn{2}{|c|}{ Trigonous } & \multicolumn{3}{|c|}{2} \\
\hline \multicolumn{2}{|c|}{ Gingiva } & \multicolumn{3}{|c|}{10} \\
\hline \multicolumn{2}{|c|}{ Lip } & \multicolumn{3}{|c|}{1} \\
\hline \multicolumn{2}{|c|}{ Palate } & & 3 & \\
\hline & N0 & N1 & N2 & Total \\
\hline $\mathrm{T} 1$ & 18 & 2 & 4 & 24 \\
\hline $\mathrm{T} 2$ & 6 & 3 & 3 & 12 \\
\hline $\mathrm{T} 3$ & 0 & 0 & 1 & 1 \\
\hline $\mathrm{T} 4$ & 4 & 0 & 1 & 4 \\
\hline Total & 28 & 5 & 9 & 42 \\
\hline
\end{tabular}

(18-22). Many brilliant strategies, some of them already one step ahead of clinical trials, have been also devised in order to inhibit this complex enzyme for anti-cancer therapy $(23,24)$.

On the basis of all these data and considerations, we planned to evaluate the role played by hTERT gene expression in human oral carcinogenesis. This study had two main objectives: i) evaluation of hTERT gene expression in the various steps of oral carcinogenesis; and ii) finding a possible correlation between hTERT gene expression, prognostic clinico-pathological parameters, and survival rate in OSCCbearing patients with appropriate molecular methodology (RT real-time PCR) and canonical immunohistochemical analytical approach (immunohistochemistry).

\section{Materials and methods}

Patients and samples. Forty-two OSCC patients were randomly chosen among those possessing a clinical follow-up of at least 3 years (Table I). Biopsies were taken from normal oral mucosa, cancerous (cancers of different histological grade and clinical stage) or precancerous (peri-tumoral dysplasia) lesions, and metastatic lymph nodes. Formalin-fixed paraffin-embedded serial sections were obtained and used for H\&E and IHC. A total of 15 specimens of oral dysplasia and 42 OSCC was obtained. Twenty-two biopsies were flash frozen in liquid nitrogen and stored at $-80^{\circ} \mathrm{C}$ for RT real-time PCR analysis. Metastatic lymph nodes were also collected.

Twenty-two normal mucosa samples were gathered from the same patients biopsing normal tissue far from tumor sites. The epithelial dysplasia grade and the histological diagnosis were established by standard criteria. Dysplasias were classified according to the WHO classification (25). Pathological staging of tumors was determined according to the TNM classification of the International Union against Cancer (UICC) (26).

RNA extraction. Twenty-four mg of deep-frozen bioptic tissue was used for total RNA extraction. Total RNA was isolated by using an RNeasy minikit (Qiagen, Hilden, Germany) according to the manufacturer's instructions. The integrity of all tested total RNA samples was verified by agarose gel electrophoresis.

Reverse transcription. Samples containing $5 \mu \mathrm{g}$ of total RNA in a final volume of $100 \mu 1$ were reverse-transcribed by avian myeloblastosis virus (AMV) reverse transcriptase (Promega, Madison, WI), according to the manufacturer's instructions. Random hexamer primers were used and the reaction was incubated for $60 \mathrm{~min}$ at $42^{\circ} \mathrm{C}$. The ss-cDNA obtained was used for real-time PCR amplification.

Real-time PCR. Real-time PCR analysis of hTERT gene expression was performed by using the $\mathrm{iCycler}^{\circledR}$ apparatus (Bio-Rad) with sequence-specific primer pairs for the genes tested. The housekeeping gene glyceraldehyde-phosphatedehydrogenase (GAPDH) was used as internal control. The primers used were the following: GAPDH forward (5'-TTG GTA TCG TGG AAG GAC TCA-3') and reverse (5'-TGT CAT CAT ATT TGG CAG GTT T-3'); hTERT forward (5'AGT GAC CGT GGT TTC TGT GT-3') and reverse (5'-TTG TCG CCT GAG GAG TAG AG-3'). The cDNA was serially diluted and every dilution was run at least in duplicate. The Real-time PCR analysis was performed as follows: initial denaturation step, $95^{\circ} \mathrm{C}$ for $3 \mathrm{~min}$ followed by 50 cycles of denaturation at $95^{\circ} \mathrm{C}$ for $1 \mathrm{sec}$; annealing, $10 \mathrm{sec}$ at $50^{\circ} \mathrm{C}$; elongation, $8 \mathrm{sec}$ at $72^{\circ} \mathrm{C}$. The IQ SYBR-Green SuperMix (Bio-Rad) was used for real-time PCR monitoring of amplification. Briefly, amplification was performed in a total volume of $20 \mu \mathrm{l}$; the reaction mix was performed with $10 \mu \mathrm{l}$ of 2X IQ SYBR-Green SuperMix, $0.5 \mu 1$ of each primer $(16 \mu \mathrm{M})$ and $2 \mu \mathrm{l}$ of cDNA (or water as control, which was always included). The real-time PCR products were run on $2 \%$ agarose gel containing TAE (standard Tris-acetateEDTA electrophoretic buffer). The amplicons of expected size were extracted, purified and controlled for sequences by Biogem DNA Sequencing Core (Biogem, Naples). Results were evaluated by ICYCLER IQ real-time Detection System Software ${ }^{\circledR}$ (Bio-Rad, Hercules, CA). Data were calculated on the basis of the threshold cycle $(\mathrm{Ct})$ value. The expression of the analyzed genes was first normalized with respect to GAPDH transcript level and then the value corresponding to each pathological sample was compared with its specific relative normal mucosa counterpart. The observed difference 
Table II. hTERT gene expression and tissue distribution of Est 2 protein.

\begin{tabular}{|c|c|c|c|c|c|}
\hline \multirow[t]{2}{*}{ Case } & & \multirow{2}{*}{$\begin{array}{l}\text { RT Real-time PCR } \\
\left(2^{\Delta \mathrm{Ct}}\right)(\text { mean } \pm \text { SEM })\end{array}$} & \multicolumn{3}{|c|}{ IHC distribution of human Est2 (mean \pm SD of $10 \mathrm{HPF}$ ) } \\
\hline & & & Atypical cells & Phlogistic cells & Cell type \\
\hline 1 & OPL & $4.00 \pm 0.50$ & $33 \pm 18$ & $5 \pm 2$ & $\mathrm{~L}, \mathrm{G}$ \\
\hline 2 & OPL & $0.50 \pm 0.03$ & $10 \pm 2^{\mathrm{a}}$ & ND & ND \\
\hline 3 & OSCC & $0.29 \pm 0.03$ & $8 \pm 2^{\mathrm{a}}$ & ND & ND \\
\hline 4 & OSCC & $9.84 \pm 1.70$ & $60 \pm 4$ & $10 \pm 4$ & $\mathrm{~L}$ \\
\hline 5 & OSCC & $0.59 \pm 0.02$ & $9 \pm 3$ & $25 \pm 3$ & $\mathrm{~L}, \mathrm{G}$ \\
\hline 6 & OSCC & $0.33 \pm 0.02$ & $20 \pm 5^{\mathrm{a}}$ & $5 \pm 3$ & $\mathrm{~L}, \mathrm{G}$ \\
\hline 7 & OSCC & $1.87 \pm 0.15$ & $35 \pm 5$ & $5 \pm 2$ & $\mathrm{~L}$ \\
\hline 8 & OSCC & $0.57 \pm 0.03$ & $5 \pm 2$ & $20 \pm 4$ & $\mathrm{~L}$ \\
\hline 9 & OSCC & $26.00 \pm 2.50$ & $80 \pm 7$ & $10 \pm 5$ & $\mathrm{~L}, \mathrm{G}$ \\
\hline 10 & OSCC & $39.00 \pm 3.40$ & $90 \pm 5$ & $80 \pm 9$ & $\mathrm{~L}$ \\
\hline 11 & OSCC & $0.17 \pm 0.01$ & $5 \pm 3$ & $25 \pm 3$ & $\mathrm{~L}$ \\
\hline 12 & OSCC & $1.23 \pm 0.08$ & $34 \pm 6$ & $30 \pm 2$ & $\mathrm{~L}, \mathrm{G}$ \\
\hline 13 & OSCC & $0.05 \pm 0.02$ & Negative & $5 \pm 3$ & $\mathrm{~L}, \mathrm{G}$ \\
\hline 14 & OSCC & ND & Negative & $5 \pm 2$ & $\mathrm{~L}$ \\
\hline 15 & OSCC & $2.5 \pm 0.2$ & $70 \pm 5$ & $23 \pm 2$ & $\mathrm{~L}$ \\
\hline 16 & OSCC & $39.4 \pm 0.24$ & $10 \pm 3$ & $22 \pm 2$ & $\mathrm{~L}$ \\
\hline 17 & OSCC & $1.7 \pm 0.4$ & $40 \pm 3$ & $10 \pm 2$ & $\mathrm{~L}$ \\
\hline 18 & OSCC & $31.5 \pm 0.7$ & $40 \pm 4$ & $45 \pm 2$ & $\mathrm{~L}$ \\
\hline 19 & OSCC & $25.9 \pm 0.25$ & $70 \pm 3$ & $24 \pm 2$ & $\mathrm{~L}$ \\
\hline 20 & OSCC & $1.8 \pm 0.06$ & $10 \pm 1$ & $12 \pm 2$ & $\mathrm{~L}, \mathrm{G}$ \\
\hline 21 & OSCC & $2.1 \pm 0.2$ & $20 \pm 2$ & $11 \pm 2$ & $\mathrm{~L}$ \\
\hline 22 & OSCC & $1.9 \pm 0.1$ & $10 \pm 1$ & $8 \pm 2$ & $\mathrm{~L}$ \\
\hline 23 & OSCC & $6.9 \pm 0.5$ & $90 \pm 5$ & $4 \pm 2$ & $\mathrm{~L}, \mathrm{G}$ \\
\hline 24 & OSCC & $1.4 \pm 0.1$ & $5 \pm 1$ & $4 \pm 2$ & $\mathrm{~L}$ \\
\hline 25 & Met L & $5.65 \pm 0.80$ & $20 \pm 3^{a}$ & - & - \\
\hline 26 & Met L & $0.35 \pm 0.04^{\mathrm{b}}$ & ND & - & - \\
\hline 27 & Met L & $4.00 \pm 0.05$ & $15 \pm 3^{a}$ & - & - \\
\hline
\end{tabular}

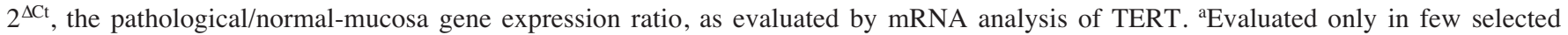
focally immunostained areas; bhistopatological analysis revealed $<70 \%$ of tumor cells spreading in the lymph node studied. IHC, immunohistochemistry; L, lymphocytes; G, polymorphonucleated granulocytes; OSCC, oral squamous cell carcinoma. OPL, oral premalignant lesion with ascertained histological dysplasia, obtained from peritumoral mucosa; Met L, lymph-node metastases; ND, not determined.

was expressed as $2^{\Delta C t}$ (pathological/normal mucosa gene expression ratio, as evaluated by mRNA analysis).

Immunohistochemistry. Four- $\mu \mathrm{m}$ serial sections from formalin-fixed and paraffin-embedded blocks were cut and mounted on poly-L-lysine-coated glass slides. Immunostaining was performed by linked streptavidin-biotin horseradish peroxidase technique (LSAB-HRP). After sequential deparaffinization and hydration, the slides were treated with $0.3 \% \mathrm{H}_{2} \mathrm{O}_{2}$ for $15 \mathrm{~min}$ to quench endogenous peroxidase. Antigen retrieval was performed by microwave heating - a first time for $3 \mathrm{~min}$ at $650 \mathrm{~W}$, a second and a third time for $3 \mathrm{~min}$ at $350 \mathrm{~W}$ - the slides immersed in $10 \mathrm{mM}$ citrate-buffer $\mathrm{pH}$ 6.0. After heating, the sections were blocked for $60 \mathrm{~min}$ with $1.5 \%$ horse serum (Santa Cruz Biotechnology) diluted in PBS buffer before reaction with the primary antibody (Ab). Primary Ab had been diluted with $0.05 \mathrm{M}$ Tris- $\mathrm{HCl}$ buffer pH 7.4 containing $1 \%$ bovine serum albumin and incubated at optimal dilution and time. The primary $\mathrm{Ab}$ and the conditions for their use were: 1:250-diluted rabbit polyclonal anti-hEst2 (EST22-A, IgG; Alpha Diagnostic International, San Antonio, TX, USA) for $120 \mathrm{~min}$ at $24^{\circ} \mathrm{C}$; the specificity of anti-Est 2 and its immunohistochemical utilization technique has been previously described (27). After two washes with PBS, the slides were treated with biotinylated species-specific secondary antibodies and streptavidin-biotin enzyme reagent (Dako, Denmark), and the color developed by 3,3'-diaminobenzidine tetrahydrochloride. Sections were counterstained with Mayer's haematoxylin and mounted using xylene-based mounting medium. Negative control slides without primary antibody were included for each staining.

The results of the immunohistochemical staining were evaluated separately by two observers. Immunostained cells were counted in at least 10 high power fields (HPF) analyzed 


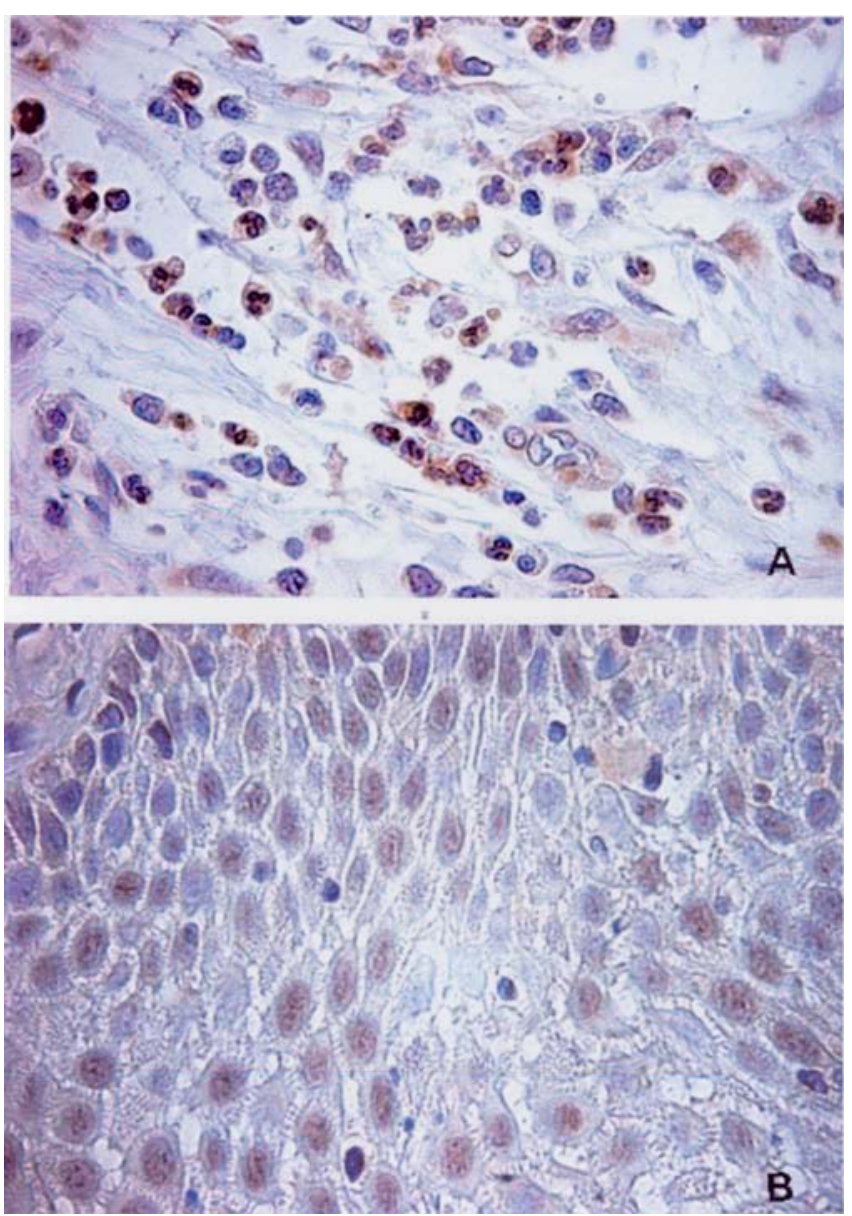

Figure 1. hTERT expression in non-neoplastic cells. (A) Immunostaining of h-TERT protein in oral tissue distant from the tumor in a patient affected by OSCC. Note the occurrence of hTERT expression in lymphocytes and granulocytes in the chorion. (B) Immunostaining of hTERT protein in oral epithelial tissue distant from the tumor in a patient affected by OSCC. The epithelium shows basal hyperplasia, spongiosis, but no cytological atypia. Interestingly, this case shows hTERT expression localized in the nuclei of almost all the cells (LSAB-HRP, x560; DNA counterstaining with haematoxylin).

by a light microscope. Staining patterns were also evaluated and recorded as nucleolar, nuclear, cytoplasmic, or diffuse nuclear and cytoplasmic.

For each case, the cumulative percentage of positive cells in all sections examined was determined. Two of the authors recorded, blindly and independently, the same slides of each case to evaluate the inter-observer variation by the K-test.

Statistical analysis. The data were analyzed by the Stanton Glantz statistical software 3 (MS-DOS) and GraphPad Prism software version 4.00 for Windows (Graph Pad software San Diego, CA, USA; www.graphpad.com). Differences between groups were determined using the one-way analysis of variance (ANOVA) and the Student-Newman-Keuls test. Only p-values $<0.05$ were considered significant. Differences in survival rate were also analyzed by Kaplan-Meier's method and differences in survival curves were studied by the $\chi^{2}$-test. Hazard ratio and $95 \%$ confidence interval were also calculated.

The survival rate curve analysis was performed only in stage I (T1N0) patients to avoid the bias introduced in mortality calculation at the advanced stage of disease.
The cut-off value for immunohistochemistry to segregate high expressing from low expressing cases was 30\% immunostained cells, as calculated by counting at least 1000 tumor cells. The cut-off value for RT real-time PCR hTERT-overexpressing cases was a number of fold increase $>1.5$ units.

\section{Results}

hTERT expression in phlogistic cells. By means of immunohistochemical staining we were able to show expression of hTERT in lymphocyte and granulocyte cells localised in the chorion beneath OSCC lesions or in tumor infiltrating lymphocytes (Table II, Fig. 1A).

hTERT expression in normal tissue of OSCC patients. Immunohistochemical staining showed focal expression of hTERT localized to basal and parabasal layers of normal epithelium. In the surrounding tumor epithelium immunostained nuclei were focally evident also in the intermediate spinous layer and in superficial layers (Fig. 1B).

hTERT activation occurs in OPL. The gene expression evaluation by real-time PCR of hTERT in different samples of OPL showed up-regulation of this gene in $50 \%$ of tested pre-malignant lesions surrounding full-blown OSCC. Immunohistochemical staining for hEst2, however, was detected in all cases of tested OPL, if positivity was detected in at least one selected high power field (HPF). The percentage of stained cells in OPL was significantly higher than in normal epithelium $(p<0.05)$. Focally, the epithelium surrounding the tumors showed immunostained nuclei also in the intermediate spinous layer and in the superficial layers. In contrast, in oral dysplasias diagnosed on the basis of classical histological parameters, all the epithelial layers (basal, intermediate-spinous and superficial) were immunostained in the great majority of cases. Furthermore, in severe oral epithelial dysplasias full thickness epithelium was stained in situ with a nuclear and cytoplasmic pattern of expression (Fig. 2A, B).

These findings show that hTERT gene expression is significantly up-regulated with an altered pattern of expression throughout the epithelium. These changes in surrounding tumor epithelium occur early in oral carcinogenesis and appear to be independent from histological diagnosis of premalignant lesion.

hTERT activation occurs in OSCC. The hTERT gene expression evaluated by real-time PCR in tumor samples was found to be up-regulated in 14 out of 21 cases $(66.7 \%)$ (Fig. 3, Table IV). These data were statistically significant if compared to 22 normal mucosa samples (ANOVA, $\mathrm{p}=0.015$; Student-NewmanKeuls, p<0.05) (Table IV). However, in 6 cases out of 21 $(28.6 \%)$ hTERT mRNA was significantly decreased, whereas in $4.7 \%$ of the cases this gene was either transcriptionally silent or expressed at a level not different from that of the normal control epithelium.

By means of immunohistochemistry hEst-2 protein was upregulated in the great majority of OSCC (Table III, Fig. 2C, D, Fig. 4). Furthermore, the immunohistochemical data indicated an hTERT distribution rather different according to the tumor histological grade (Fig. 5), onset site (Fig. 6) and size (Fig. 7). 

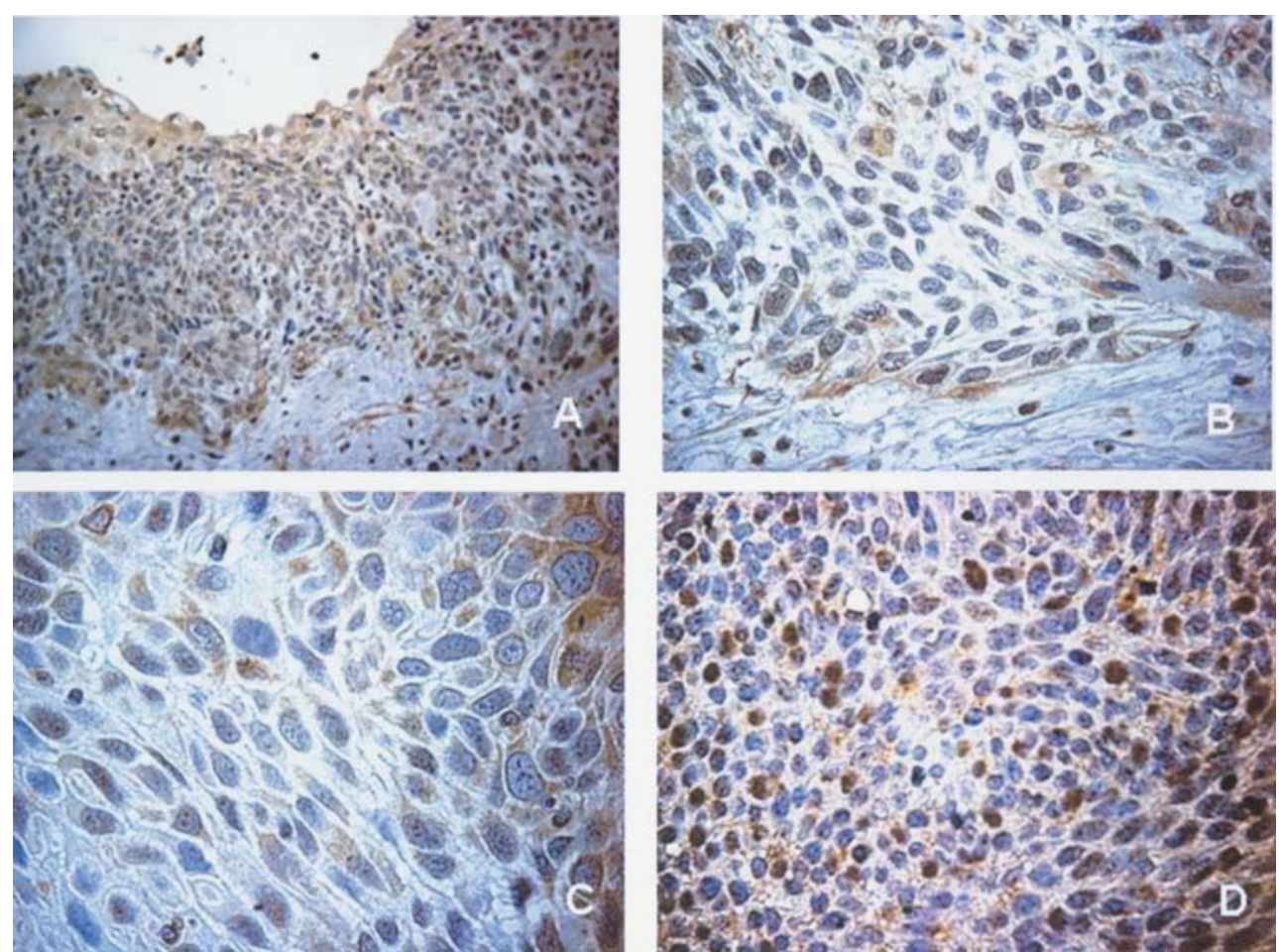

Figure 2. hTERT expression in oral carcinogenesis. (A) A case of severe dysplasia showing nuclear hTERT expression in most atypical cells. Note also the positive immunostaining of lymphocytes beneath the lesion (LSAB-HRP, x100; DNA counterstaining with haematoxylin). (B) A detail of picture A at higher magnification showing the nuclear expression of hTERT in atypical cells (LSAB-HRP, x200; DNA counterstaining with haematoxylin). (C) A case of well/moderately differentiated OSCC showing retained desmosomes and other architectural characteristics of squamous epithelium, but with high nuclear hyperchromatism, pleomorphism. Note high hTERT expression in cancer cells (LSAB-HRP, x400; DNA counterstaining with haematoxylin). (D) A case of poorly differentiated OSCC showing loss of architectural characteristics of squamous epithelium, retaining only focal desmosomes, high nuclear/cytoplasmic ratio, but with high nuclear hyperchromatism and pleomorphism. hTERT-immunostained nuclei are detectable in at least 30\% of cells (LSAB-HRP, x200; DNA counterstaining with haematoxylin).

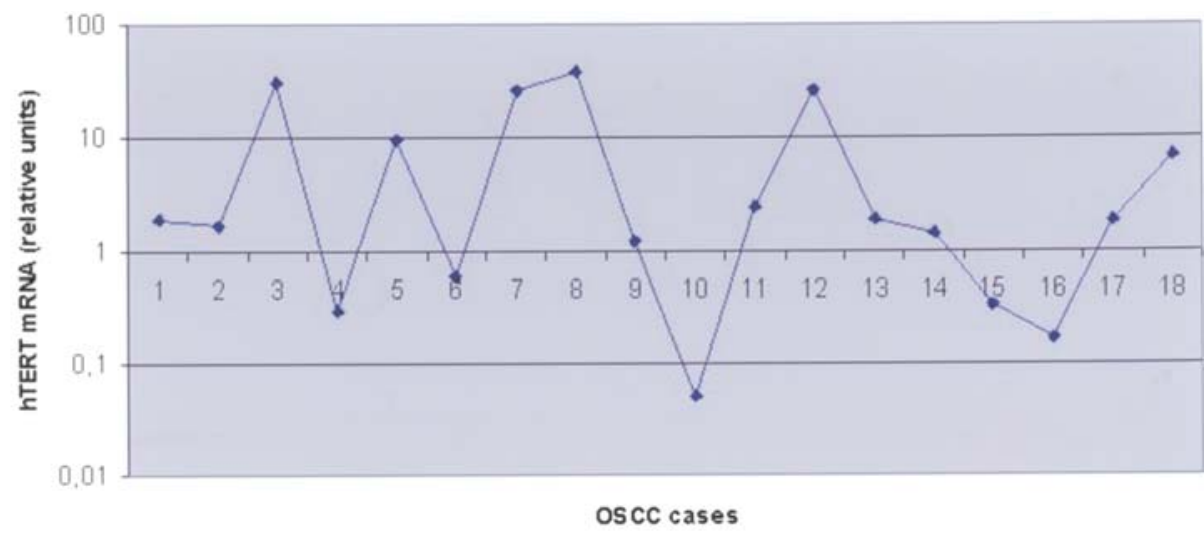

Figure 3. Quantitative deregulation of hTERT RNA in OSCC. Real-time PCR analysis of RNA isolated from pathological samples of OSCC compared to matched normal mucosa.

Table III. Statistical evaluation of hTERT protein expression in OSCC as evaluated by immunohistochemistry.

\begin{tabular}{lcccc}
\hline Groups & $\mathrm{N}$ & $\begin{array}{c}\text { Mean } \pm \text { SEM } \\
\mathrm{Ct}\end{array}$ & ANOVA & Student-Newman-Keuls \\
\hline 1) Normal epithelium & 22 & $10.0 \pm 0.75$ & $\mathrm{p}=0.006$ & $\mathrm{p}<0.05$ \\
2) OSCC & 42 & $23.7 \pm 3.48$ & & \\
\hline
\end{tabular}

Group 1, hTERT positive cells of normal epithelium. Group 2, hTERT positive cells of OSCC samples. 
Table IV. Statistical evaluation of hTERT gene expression in OSCC as evaluated by RT real-time PCR.

\begin{tabular}{lcccc}
\hline Groups & $\mathrm{N}$ & $\begin{array}{c}\text { Mean } \pm \text { SEM } \\
\mathrm{Ct}\end{array}$ & ANOVA & Student-Newman-Keuls \\
\hline 1) Normal epithelium & 22 & $26.5 \pm 0.61$ & $\mathrm{p}=0.015$ & $\mathrm{p}<0.05$ \\
2) OSCC & 22 & $23.87 \pm 0.86$ & & \\
\hline
\end{tabular}

Group 1, h-TERT/GAPDH normalized Ct values of normal epithelium samples. Group 2, h-TERT/GAPDH normalized Ct values of OSCC samples. SEM, standard error of means.

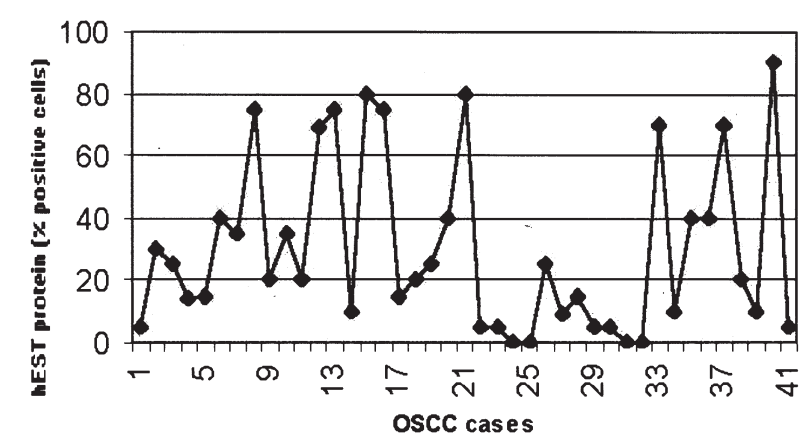

Figure 4. Quantitative deregulation of hTERT protein in OSCC as evaluated by immunohistochemistry.

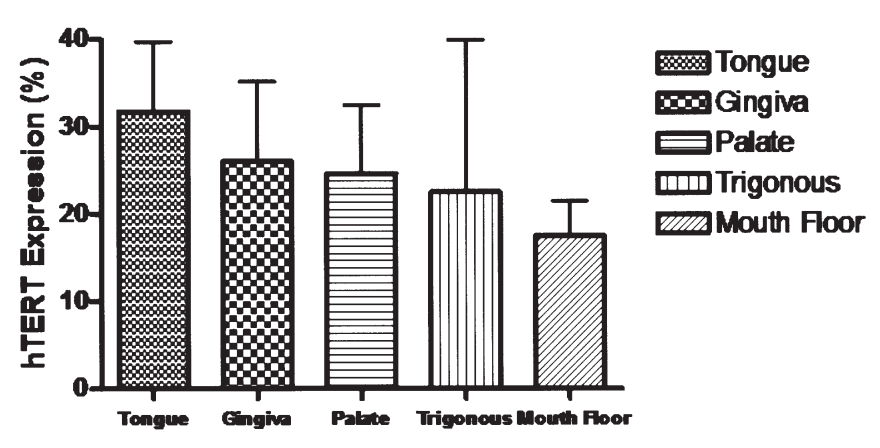

Figure 6. Immunohistochemical expression of hTERT (hEST-2) in 42 cases of OSCC grouped according to the site of localization in oral cavity.

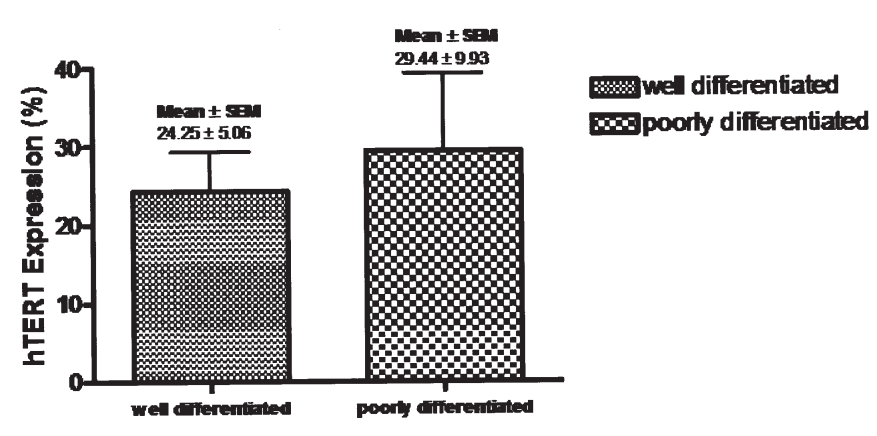

Figure 5. Immunohistochemical expression of hTERT (hEST-2) in 42 cases of OSCC grouped according to the degree of histological differentiation.

The highest gene expression level has been found in low differentiated tumors (mean $\pm \mathrm{SEM}=29.44 \pm 9.93$ ) rather than in those well differentiated (mean $\pm \mathrm{SEM}=24.25 \pm 5.06$ ) and in neoplasms with a size higher than $1.5 \mathrm{~cm}$ rather in those with sizes smaller or equal to this value (mean $\pm \mathrm{SEM}=$ $34.94 \pm 7.07)$. The comparison between the hTERT gene expression data and the clinico-pathological findings is, however, not statistically significant.

In contrast, by separating the patients into two groups on the basis of their high or low level of hTERT expression evaluated at both mRNA and protein level, we were able to demonstrate statistically significant differences in stage I (T1N0) patients (Figs. 8 and 9).

The survival rate of high hTERT expressing patients decreased early after initial surgical treatment because of locoregional recurrences and metastases (Figs. 8 and 9).

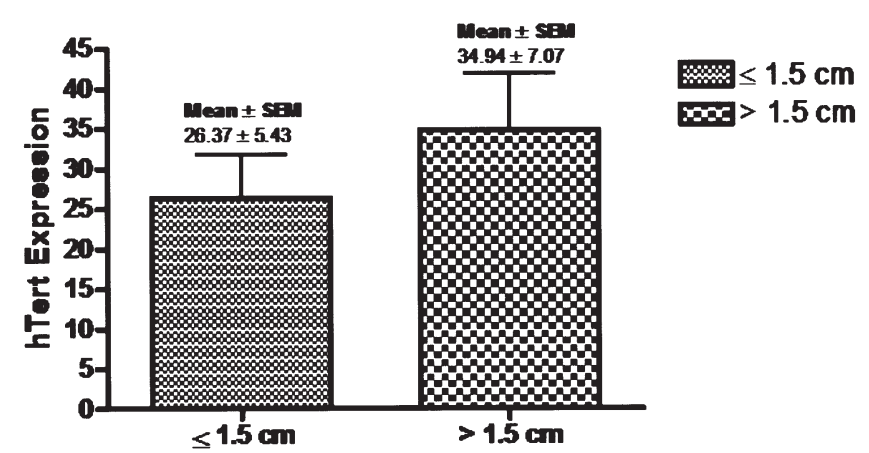

Figure 7. Immunohistochemical expression of hTERT (hEST-2) in 42 cases of OSCC grouped according to tumor size.

The 3-year average survival of high hTERT-expression patients was 2 months, which vas significantly lower than that of the low hTERT-expression patients (16 months) $\left(\mathrm{p}=0.04 \chi^{2}\right.$-test; OR 95\% CI of ratio $=1.105$-19930) $($ Fig. 8). This difference has been further confirmed in a higher number of cases analyzed at protein level by immunohistochemical techniques $\left(\mathrm{p}=0.03 \chi^{2}\right.$-test; OR 95\% CI of ratio $=0.03072$ 0.9019) (Fig. 9).

\section{Discussion}

In human epithelium three principal and overlapping tumor suppressor barriers [the p16 ${ }^{\mathrm{INK} 4 \mathrm{a}}$-retinoblastoma protein (p16 INK4a-Rb) pathway; the ARF-p53 pathway; telomeres] appear to be operative. The role of tumor suppressor inhibition has been demonstrated also in oral carcinogenesis, in which 


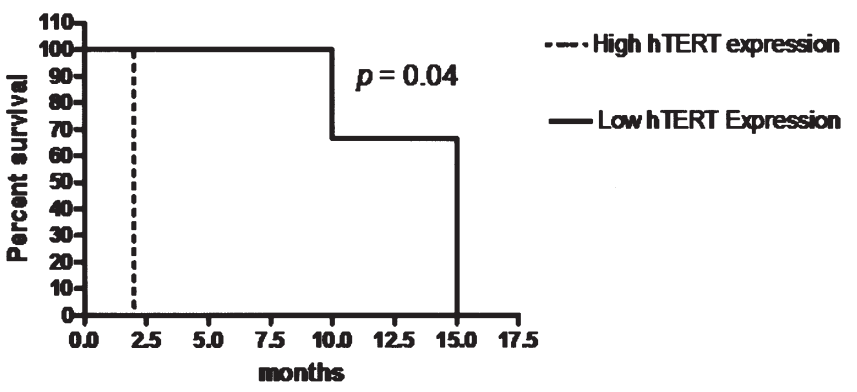

Figure 8. Overall survival rate in stage I patients according to hTERT expression as evaluated by real-time PCR. High hTERT expression patients (dotted line) showed a survival rate worse than that of low hTERT expression patients (solid line).

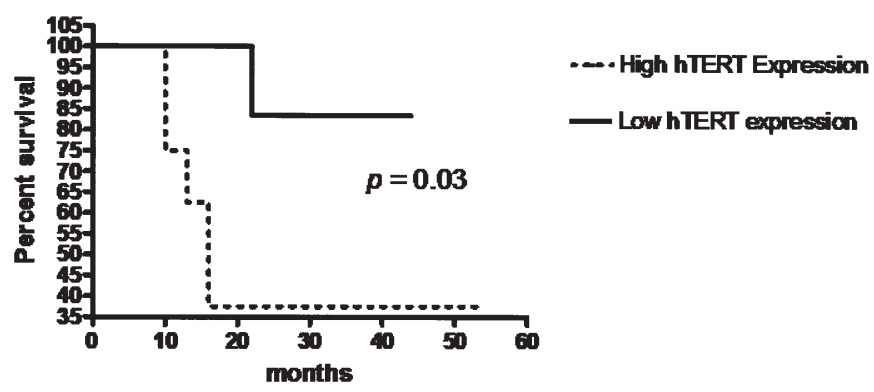

Figure 9. Overall survival rate of patients in stage I according to hTERT expression as evaluated by immunohistochemistry. High hTERT expression patients (dotted line) showed a worse survival than that of low hTERT expression patients (solid line).

both p16 ${ }^{\mathrm{INK} 4 \mathrm{a}}$-retinoblastoma protein ( $\left.16^{\mathrm{INK} 4 \mathrm{a}}-\mathrm{Rb}\right)$ and ARFp53 pathways have been shown to be actively engaged $(28,29)$. However, only few molecular studies have been performed on the activation state of the TMM in oral carcinogenesis (16).

The repression of telomerase in mammalian cells results in shortening of telomeres with each cell division, and ultimately in chromosomal instability, aging, and cell death (30).

According to the classical paradigm of initiation-promotionprogression with its contention of involvement of mortal differentiated cells as target in the initiation process, it is postulated that, at some point during the multistep process of carcinogenesis, evolving pre-malignant cell populations exhaust their endowment of allowed doublings and accomplish their tumorigenic program by breaching the mortality barrier and acquiring unlimited replicative potential. However, this model has been recently disputed since, according to the cancer stem cell theory, the stem cells or their early progenitors have been suggested to be the real target in the initiation event. The stem cells are naturally immortal and became mortal only when they are induced to terminally differentiate and lose their telomerase activity. Consequently, the initiation process is one that stably and irreversibly inhibits the mortalization of the stem cell (31). Stem cells are defined as having the capacity to divide both symmetrically, producing two daughter cells that are stem cells, and asymmetrically, producing one daughter cell that terminally differentiates and the other that maintains 'stemness'. Therefore, within the concept of initiation of a stem cell, the first step of carcinogenesis is to block asymmetric cell division without interfering with the cell's ability to divide symmetrically.

If the original target cell in the initiation process is a mortal cell, its telomerase activity has been repressed and its telomeres have been lost during the normal tissue differentiation process. Therefore, to immortalize a terminally differentiated or a committed cell means mainly to re-establish telomerase activity and restore telomere length.

The conceptual problem of whether the telomerase activity in cancer is restored in a differentiated or committed cell or if it is preserved in the clonal espansion of a mutated stem cell, is crucial to the understanding of carcinogenesis and to envision the future of cancer therapy. This problem is also complicated by the fact that the heterogeneous tumor tissue contains functionally different subpopulations of cells: a mixture of non-neoplastic cells, non-tumorigenic cancer cells, and cancer stem cells. Furthermore, in some cases cancer stem cells might arise from the mutational transformation of normal stem cells, whereas in other cases mutations may cause restricted progenitors or differentiated cells to acquire properties of cancer stem cells such as self-renewal potential.

As we have already mentioned, telomerase expression is low or absent in most human somatic tissues, with its expression principally restricted in the adult to the activated lymphocytes, germ cells, and tissue stem cells. The restricted pattern of telomerase activity relates primarily to the strict regulation of TERT gene transcription, whereas the expression of the gene coding for the RNA component of telomerase (TERC) is broader in distribution. However, telomere maintenance is evident in virtually all types of malignant cells. It has been found that $85-90 \%$ of them maintain telomere length by up-regulating expression of the telomerase enzyme, which adds hexanucleotide repeats onto the ends of telomeric DNA, while the remainder have invented a way of activating a mechanism, termed ALT, which appears to maintain telomeres through recombination-based inter-chromosomal exchanges of sequence information. Both mechanisms seem to be strongly suppressed in most normal human cells in order to deny them unlimited replicative potential. In contrast, telomere length abnormalities appear to be one of the earliest and most prevalent genetic alterations acquired in the multistep process of malignant transformation. In fact, Meeker et al reported that, in epithelial carcinogenesis, the percentage of intraepithelial neoplasia lesions showing telomere length abnormalities is $95.6 \%$ (32). The implications of these findings include the potential that telomere length assessment in situ may be a widely useful biomarker for monitoring disease prevention strategies and for improved early diagnosis (32).

The induction of hTERT expression has been reported to be progressive and to occur throughout the entire process of oral carcinogenesis $(33,34)$.

Our study demonstrated that the normal strict regulation of hTERT gene transcription is widely deregulated in the cancer cells of OSCC, since it appears to be highly up-regulated in $66.7 \%$ of analyzed tumors. Only in $<5 \%$ of tumors is this gene unaltered or undetectable. The marked levels of hTERT gene expression have been further confirmed by immunohistochemistry analysis in an even higher number of cases. Furthermore, immunohistochemical study of hEst-2 protein 
demonstrated not only overexpression in $50 \%$ of pre-cancerous lesions and in $90 \%$ of OSCC but also an altered expression pattern of hTERT protein both in OPL and in OSCC.

In our study, hTERT expression was detectable in some cases of peritumoral normal-appearing tissues and in dysplastic tissues of patients who further developed oral cancer. Furthermore, our results are in part inconsistent with a previous report (35), which demonstrated telomerase activity by TRAP assay in human oral tissues with moderate or higher grade of dysplasia but not in those with mild dysplasia, since we have found a very early expression of hTERT in the process of oral carcinogenesis. In this study, hTERT expression was detected in the basal cells of normal oral mucosa, and the cells expressing this protein were also seen in the upper layer of oral pre-malignant epithelium. These data are in agreement with other reports indicating that there are at least two steps in the increase of telomerase activity during carcinogenesis in oral squamous cells: i) a change in the distribution of cells expressing telomerase; and ii) an overexpression of hTERT in individual cells (36).

Interestingly, our study showed up-regulation and an altered pattern of expression of hTERT not only in dysplasias and carcinoma in situ, but also in epithelial tissues with changes not fulfilling all the histological criteria for dysplasia. These findings suggest that hTERT may be a useful additional marker to detect patches of epithelium at high risk for developing further genetic changes, leading to invasive cancer, especially if it is used together with other accredited markers in defining the carcinogenesis risk.

Furthermore, the present study demonstrates that great caution is required in diagnosis of pre-cancerous lesions or cancer based only on a molecular biology approach even if a high-sensitivity assay such as real-time PCR and an 'hallmark' of cancer such telomerase are employed, since a considerable number of false negatives are known to exist.

Our data, in line with previous studies (37), demonstrate that there is no significant relationship between hTERT expression and several clinico-pathological parameters, such as tumor stage, size, and histological grade. Several authors, however, have suggested that telomerase activation is an early event during neoplastic transformation in vivo and is frequently related to the proliferation rate of cancer cells $(38,39)$. At later stages, many solid malignant tumors, most probably as a consequence of a critical size increase and insufficient vascularization, become necrotic in their central region and are associated to a marked down-regulation of hTERT gene expression (39).

It is on the basis of these data and considerations that we decided to evaluate the survival rate only in stage I (T1N0) patients by comparing this vital parameter in individuals with high levels of hTERT expression vs. those endowed with low levels of expression. The statistically significant differences observed suggest the critical value of our findings in the clinicotherapeutical decisions concerning these patients. It is well known, in fact, that whilst in T2-T4 patients neck dissection is indicated as elective or therapeutical, in the T1N0 patient, even though the diagnostic procedures of clinical staging are widely improved, elective neck dissection is still controversial due to the high morbidity and mortality risks related to this type of surgical intervention (40-45).

\section{Acknowledgements}

This study was supported in part by grants from MIUR-PRIN 2004, Università degli Studi di Foggia, and Fondazione Cassa di Risparmio di Verona, Vicenza, Belluno e Ancona 2004, Italy.

\section{References}

1. Kim NW, Piatyszek MA, Prowse KR, et al: Specific association of human telomerase activity with immortal cells and cancer. Science 266: 2011-2015, 1984.

2. Meyerson M, Counter CM, Eaton EN, et al: hEST2, the putative human telomerase catalytic subunit gene, is up-regulated in tumor cells and during immortalization. Cell 90: 785-795, 1997.

3. Nakamura TM, Morin GB, Chapman KB, et al: Telomerase catalytic subunit homologs from fission yeast and human. Science 277: 955-959, 1997.

4. Harley $\mathrm{CB}$, Futcher $\mathrm{AB}$ and Greider $\mathrm{CW}$ : Telomeres shorten during ageing of human fibroblasts. Nature 345: 458-460, 1990.

5. Hastie ND, Dempster M, Dunlop MG, Thompson AM, Green DK and Allshire RC: Telomere reduction in human colorectal carcinoma and with ageing. Nature 346: 866-868, 1990.

6. Wright WE, Piatyszek MA, Rainey WE, Byrd W and Shay JW: Telomerase activity in human germline and embryonic tissues and cells. Dev Genet 18: 173-179, 1996.

7. Eisenhauer KM, Gerstein RM, Chiu CP, Conti M and Hsueh AJ: Telomerase activity in female and male rat germ cells undergoing meiosis and in early embryos. Biol Reprod 56: 1120-1125, 1997.

8. Liu K, Schoonmaker MM, Levine BL, June CH, Hodes RJ and Weng NP: Constitutive and regulated expression of telomerase reverse transcriptase (hTERT) in human lymphocytes. Proc Natl Acad Sci USA 96: 5147-5152, 1999.

9. Kyo S, Kanaya T, Takakura M, Tanaka M, Yamashita A, Inoue H and Inoue M: Expression of human telomerase subunits in ovarian malignant, borderline and benign tumors. Int J Cancer 80: 804-809, 1999.

10. Tahara H, Yasui W, Tahara E, et al: Immuno-histochemical detection of human telomerase catalytic component, hTERT, in human colorectal tumor and non-tumor tissue sections. Oncogene 18: 1561-1567, 1999.

11. Ramakrishnan S, Eppenberger U, Mueller H, Shinkai Y and Narayanan R: Expression profile of the putative catalytic subunit of the telomerase gene. Cancer Res 58: 622-625, 1998.

12. Counter CM, Hahn WC, Wei W, et al: Dissociation among in vitro telomerase activity, telomere maintenance, and cellular immortalization. Proc Natl Acad Sci USA 95: 14723-14728, 1998.

13. Counter CM, Meyerson M, Eaton EN, Ellisen LW, Caddle SD, Haber DA and Weinberg RA: Telomerase activity is restored in human cells by ectopic expression of hTERT (hEST2), the catalytic subunit of telomerase. Oncogene 16: 1217-1222, 1998.

14. Hahn WC, Counter CM, Lundberg AS, Beijersbergen RL, Brooks MW and Weinberg RA: Creation of human tumor cells with defined genetic elements. Nature 400: 464-468, 1999.

15. Hanahan D and Weinberg RA: The hallmarks of cancer. Cell 100: 57-70, 2000.

16. Muntoni A, Fleming J, Gordon KE, Hunter K, McGregor F, Parkinson EK and Harrison PR: Senescing oral dysplasias are not immortalized by ectopic expression of hTERT alone without other molecular changes, such as loss of INK4A and/or retinoic acid receptor-beta: but $\mathrm{p} 53$ mutations are not necessarily required. Oncogene 22: 7804-7808, 2003.

17. Goessel G, Quante M, Hahn WC, et al: Creating oral squamous cancer cells: a cellular model of oral-esophageal carcinogenesis. Proc Natl Acad Sci USA 102: 15599-15604, 2005

18. Sebastian S, Grammatica L and Paradiso A: Telomeres, telomerase and oral cancer (Review). Int J Oncol 27: 1583-1596, 2005.

19. Koscielny S, Eggeling F, Dahse R and Fiedler W: The influence of reactivation of the telomerase in tumour tissue on the prognosis of squamous cell carcinomas in the head and neck. J Oral Pathol Med 33: 538-542, 2004.

20. Yajima Y, Noma H, Furuya Y, et al: Quantification of telomerase activity of regions unstained with iodine solution that surround oral squamous cell carcinoma. Oral Oncol 40: 314-320, 2004. 
21. Zhong LP, Chen GF, Xu ZF, Zhang X, Ping FY and Zhao SF: Detection of telomerase activity in saliva from oral squamous cell carcinoma patients. Int J Oral Maxillofac Surg 34: 566-570, 2005.

22. Fujita $H$, Nagata $M$, Hoshina $H$, et al: Clinical significance and usefulness of quantification of telomerase activity in oral malignant and nonmalignant lesions. Int J Oral Maxillofac Surg 33: 693-699, 2004

23. Zhang P, Xu Q, Chen WT, Duan LQ, Zhang ZY and Zhou XJ: Synergistic down-regulation of telomerase by all-trans retinoic acid and antisense oligonucleotide in oral squamous cell carcinoma cell line (Tca8113). Oral Oncol 41: 909-915, 2005.

24. Murakami J, Asaumi J, Kawai N, et al: Effects of histone deacetylase inhibitor FR901228 on the expression level of telomerase reverse transcriptase in oral cancer. Cancer Chemother Pharmacol 56: 22-28, 2005.

25. Pindborg JJ, Reichart PA, Smith CJ and van der Waal I: Histological Typing of Cancer and Precancer of the Oral Mucosa. In: World Health Organization International Histological Classification of Tumors. 2nd edition. Springer-Verlag, Berlin, Heidelberg, New York, pp9-29, 1997.

26. International Union Against Cancer: TNM Classification of Malignant Tumors. Wiley-Liss, New York, 2000.

27. Hiyama E, Hiyama K, Yokoyama T and Shay JW: Immunohistochemical detection of telomerase (hTERT) protein in human cancer tissues and subset of cells in normal tissues. Neoplasia 3: 17-26, 2001.

28. Soni S, Kaur J, Kumar A, et al: Alterations of rb pathway components are frequent in patients with oral epithelial dysplasia and predict clinical outcome in patients with squamous cell carcinoma. Oncology 68: 17-26, 2005.

29. Bradley G, Irish J, MacMillan C, et al: Abnormalities of the ARF-p53 pathway in oral squamous cell carcinoma. Oncogene 20: $654-658,2001$

30. Gonzalo S, Jaco I, Fraga MF, Chen T, Li E, Esteller M and Blasco MA: DNA methyltransferases control telomere length and telomere recombination in mammalian cells. Nat Cell Biol 8: 416-424, 2006.

31. Trosko JE and Tai MH: Adult stem cell theory of the multistage, multi-mechanism theory of carcinogenesis: role of inflammation on the promotion of initiated stem cells. Contrib Microbiol 13: 45-65, 2006.

32. Meeker AK, Hicks JL, Iacobuzio-Donahue CA, et al: Telomere length abnormalities occur early in the initiation of epithelial carcinogenesis. Clin Cancer Res 10: 3317-3326, 2004.
33. Liao J, Mitsuyasu T, Yamane K and Ohishi M: Telomerase activity in oral and maxillofacial tumors. Oral Oncol 36: 347-352, 2000 .

34. Hae-Ryun K, Russell C, Park N, Sapp P, Mo KK and Park N: Elevated expression of hTERT is associated with dysplastic cell transformation during human oral carcinogenesis in situ. Clin Cancer Res 7: 3079-3086, 2001.

35. Miyoshi Y, Tsukinoki K, Imaizumi T, et al: Telomerase activity in oral cancer. Eur J Cancer Part B Oral Oncol 35: 283-289, 1999.

36. Fujimoto R, Kamata N, Yokoyama K, Ueda N, Satomura K, Hayashi E and Nagayama M: Expression of telomerase components in oral keratinocytes and squamous cell carcinomas. Oral Oncol 37: 132-140, 2001.

37. Lee BK, Diebel E, Neukam FW, Wiltfang J and Ries J: Diagnostic and prognostic relevance of expression of human telomerase subunits in oral cancer. Int J Oncol 19: 1063-1068, 2001.

38. Sumida T and Hamkawa H: Telomerase and oral cancer. Oral Oncol 37: 333-340, 2001

39. Falchetti ML, Pallini R, D'Ambrosio E, et al: In situ detection of telomerase catalytic subunits mRNA in glioblastoma multiforme. Int J Cancer 88: 895-901, 2000.

40. Vandenbrouck C, Sancho-Garnier H, Chassagne D, Saravane D, Cachin Y and Micheau C: Elective versus therapeutic radical neck dissection in epidermoid carcinoma of the oral cavity: results of a randomized clinical trial. Cancer 46: 386-390, 1980.

41. Akih AR, Rao RS, Borges AM and Patel AR: Elective versus therapeutic neck dissection in early carcinoma of the oral tongue. Am J Surg 158: 309-313, 1989.

42. Yii NW, Patel SG, Rhys-Evans PH and Breach NM Management of the NO neck in early cancer of the oral tongue. Clin Otolaryngol 24: 75-79, 1999.

43. Duvvuri U, Simental AA Jr, D'Angelo G, Johnson JT, Ferris RL, Gooding W and Myers EN: Elective neck dissection and survival in patients with squamous cell carcinoma of the oral cavity and oropharynx. Laryngoscope 114: 2228-2234, 2004.

44. Kligerman J, Lima RA, Soares JR, Prado L, Dias FL, Freitas EQ and Olivatto LO: Supraomohyoid neck dissection in the treatment of T1/T2 squamous cell carcinoma of oral cavity. Am J Surg 168: 391-394, 1994

45. Dias FL, Kligerman J, Matos de Sa G, et al: Elective neck dissection versus observation in stage I squamous cell carcinomas of the tongue and floor of the mouth. Otolaryngol Head Neck Surg 125: 23-29, 2001. 